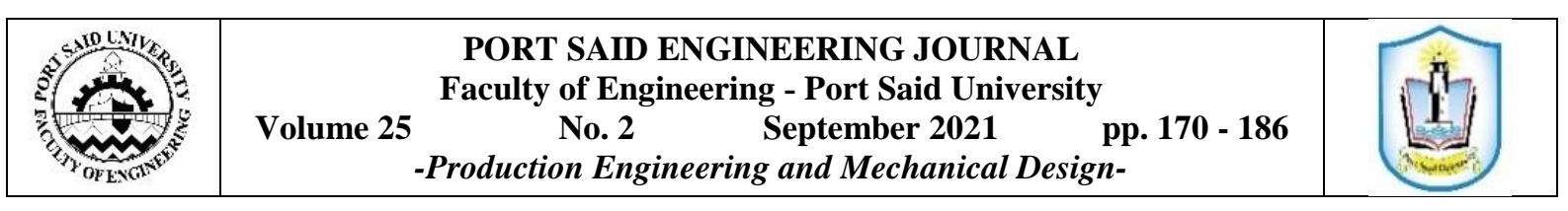

\title{
Comparing Mitigation Strategies for Supply Chain under Operational Disruptions Using Monte Carlo Simulation
}

\author{
Raghda Taha ${ }^{1}$, Amin El-Kharbotly², Yomna Sadek ${ }^{3}$
}

\begin{abstract}
Although supply chain disruptions have been under study since the 1990's, they attracted more attention last year due to the COVID-19 pandemic. Not only researchers, but all people realized how disruptions can negatively affect the performance of business, and supply chains. Mitigation strategies are the way to "be better prepared" for such disruptions. This paper aims at evaluating the performance of five different mitigation strategies for a multi-period supply chain under operational disruptions. The disruptions under consideration are capacity, and demand disruptions, whether separate or simultaneous. Integer linear programming is used to design the supply chain network. Monte Carlo simulation is used to evaluate the performance of the proposed mitigation strategies under different disruption scenarios. Results reveal that the mitigation strategies that perform better regarding financial performance measures, perform worse regarding customer satisfaction performance measures. The model helps decision makers to decide the most suitable mitigation strategy according to their priorities.
\end{abstract}

Keywords: Supply chain, multi-interval, disruptions, simulation, mitigation strategies

\section{Nomenclature}

\begin{tabular}{|c|c|c|}
\hline$\delta$ & : & Demand variation percentage \\
\hline$h$ & & Unit holding cost of product \\
\hline$n$ & & $\begin{array}{l}\text { A supply chain network design, } \mathrm{n}= \\
{[1,2,3, \ldots \mathrm{N}]}\end{array}$ \\
\hline$n^{\prime}$ & & $\begin{array}{l}\text { Number of periods when the fill } \\
\text { rate was } 100 \%, 1 \leq n^{\prime} \leq T\end{array}$ \\
\hline$P$ & & $\begin{array}{l}\text { Total number of potential plants } \mathrm{p}= \\
{[1,2,3 \ldots \mathrm{P}]}\end{array}$ \\
\hline$S$ & & Disruption scenario $\mathrm{s}=[1,2,3, \ldots \mathrm{S}]$ \\
\hline$T$ & & Periods of planning $\mathrm{t}=[1,2,3 \ldots \mathrm{T}]$ \\
\hline$U$ & & Unit unutilized capacity cost \\
\hline Cost & & $\begin{array}{l}\text { Total cost of operating the supply } \\
\text { chain }\end{array}$ \\
\hline$P C$ & & Unit production cost \\
\hline$S C$ & & $\begin{array}{l}\text { Losses per unit for shortage in } \\
\text { customers' demand }\end{array}$ \\
\hline$S P$ & & Unit selling price of product \\
\hline
\end{tabular}

1 Assistant Professor, Department of Supply Chain Management, College of international transport and logistics, Arab Academy for Science Technology and Maritime Transport Cairo, Egypt, email: raghda.bahaa@aast.edu

${ }^{2}$ Professor, Design and Production Engineering Department, Faculty of Engineering, Ain Shams University, Cairo, Egypt, email: amin_elkharbotly@eng.asu.edu.eg

3 Assistant Professor, Design and Production Engineering Department, Faculty of Engineering, Ain Shams University, Cairo, Egypt, email: yomna.sadek@eng.asu.edu.eg

Received: 27-02-2021, Accepted: 27-05-2021 DOI : 10.21608/PSERJ.2021.65383.1096
AvgDem $_{t}$ : Average demand during period $t$ for undisrupted case

$\operatorname{Cap}_{p} \quad$ : Regular capacity of plant $p$

$\operatorname{Cap}_{p}^{\prime} \quad$ : Overtime capacity of plant $p$

Capsur $_{p t}$ : Surplus capacity of plant $p$

Cost $_{s}$ : Total cost of supply chain under disruption scenario (s)

Dem $_{t} \quad$ : Demand value during period $t$

$F C_{p} \quad:$ Fixed cost of operating plant $p$

$P_{s} \quad:$ Probability of scenario (s)

$R_{p} \quad: \quad$ Reduced quantity from capacity of plant $(p)$ due to disruption

Qdel $_{t} \quad$ : Quantities of product delivered to the customer during period $t$

$Q_{\text {dis }} \quad$ : Total quantities that were not satisfised from the customer demand

Qext $t_{p t} \quad$ : Extra quantities produced at plant $p$ than the demand during period $t$

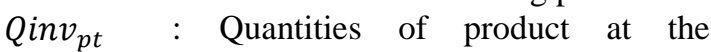
inventory of plant $p$ during period $t$

Qinv ${ }_{p t}^{\prime} \quad$ : Quantities used from the inventory of plant $p$ during period $t$

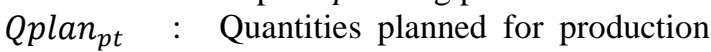
at plant $p$ during period $t$

$\operatorname{Qprod}_{p t} \quad$ : Actual quantities produced at plant $p$ during period $t$

$\operatorname{Qprod}_{p t}^{\prime}$ : Quantities produced using the overtime capacity of plant $p$ during period $t$

$Q^{\prime}$ sur $_{p t}$ : Quantities produced using the surplus capacity of plant $p$ during period $t$

$T C_{p} \quad: \quad$ Unit transportation and production cost at plant $p$

$T C^{\prime}{ }_{p} \quad$ : Unit transportation and overtime production cost at plant $p$ 


\section{INTRODUCTION}

Supply chain management was introduced in the early 1980 s by Oliver and Webber [1] in order to respond to fierce competition among companies. It took years for corporations to realize how important it is to integrate their operations into successful supply chains. This led to extensive supply chain management studies in the middle 1990's trying to figure out the reality about supply chains. La Londe [2] published an article in 1997 entitled "Supply Chain Management: Myth or Reality?". By the end of the 1990's supply chain management was one of the hottest topics under research. At that time, simple supply chain networks were considered. With the advancement of the computational machines, more complicated constraints and assumptions were added to the supply chain models.

One of the supply chain topics that researchers studied extensively was the supply chain under disruptions. The supply chain disruptions have negative impact on the financial and operational performance of the entire supply chain as well as the supply chain members. In their study, Kumar et al [3] showed the implications of COVID-19 pandemic on sustainable production and consumption trends. They stated that the availability and production of many essential products like grocery and pharmaceutical products were drastically reduced and created a huge mismatch between supply and demand. It was found that the resilience of the supply chain network to the pandemic was very poor, and that nearly $35 \%$ of the manufacturer reported failure in their supply chain network due to global coronavirus pandemic. For this reason, research goes through several study directions to investigate different disruption types and find methods to deal with them.

Following is a literature review for the recent research studying supply chain under disruption. First, research articles are presented followed by review articles. Finally, a summary for all the literature review with comparisons are presented.

Snyder et al. [4] defined disruptions as "random events that cause a supplier or other element of the supply chain to stop functioning, either completely or partially, for a (typically random) amount of time". The literature classifies the disruption according to the location of the disruption into supplier disruption, facility disruption, distributor centre disruption, or a combination of the previous. It is also classified according to the type of disruption into operational disruptions, and disruption risks. The operational risks deal with the day-to-day disturbances in the supply chain operations e.g. lead-time and demand fluctuations. However, the disruption risks belong to low-frequency-high-impact events e.g., tsunami in Japan in 2011 and its huge impact on the supply chain worldwide, the explosion at BASF factory in 2016 in Germany and the shortage of raw materials in global supply chains.

Ivanov [5] presented a simulation-based study to identify the sustainability factors that mitigate and the factors that enhance the ripple effect in the supply chain. His results indicated that the sustainable single sourcing enhances the ripple effect, whereas facility fortification at major employers in regions mitigates the ripple effect and enhances sustainability. The results also indicated that reduction in facility storage in the supply chain downstream of a disruption-risky facility increases the sustainability but causes the ripple effect.

Giri and B. R. Sarker [6] considered the Third-Party Logistics (TPL). The supply chain consisted of a monopolistic manufacturer, a third-party logistics service provider, and multiple retailers. The production was subject to unexpected disruptions, whereas the demand was uncertain. Their model considered buyback and revenue sharing contracts. They found that production disruption and third-party logistics had impacts on the performance of the supply chain. They also found that buyback and revenue sharing contracts tended to emerge indifferent in case of high probability of disruption.

Hasani and Khosrojerdi [7] proposed six mitigation strategies. These strategies were facility dispersion, facility reinforcement, production of semi-manufactured products, multiple sourcing, keeping an inventory, and considering primary and alternative bill of material. They developed a mixed-integer non-linear model to design robust global supply chain networks under uncertainty with the objective to maximize the net profit (after-tax) for the global supply chain network under normal and disrupted conditions at the same time. Their results revealed that among the six strategies three strategies; namely facility reinforcement, multiple sourcing, and facility dispersion, had the most significant impact on the global supply chain performance.

Taha et al. [8] formulated a multi-objective model Goal programming for robust optimization of a multi-product supply chain design problem. The objectives were to maximize contribution, minimize the investment and disruptions costs. Their mitigation strategy proposed was to have continuous installment of production modules with the increase of demand. The results proved that the strategy helps reduce considerably the investment cost represented by the present worth.

Chen and Xiao [9] considered the manufacturer under production disruption risks and uncertainty of capacity allocation. Two extreme cases were clear; when the disruption risk is low and the production capacity is large the manufacturer will not outsource; when the disruption risk is high, the manufacturer will fully outsource production whatever the production capacity is. For the zone of order-difference outsourcing, the manufacturer just outsources the part in excess of the threshold value. Here, they compared two supply chain game models: retailerStackelberg (RS) game and manufacturer- Stackelberg (MS) game. Under the RS game, the retailer was induced to order more items. Under the MS game, the retailer always ordered the quantity of the classic newsvendor model.

Felice et al. [10] also used the outsourcing strategy. They proposed a multi-criteria tool to monitor and to improve the supply chain performance. They integrated the "Balanced Scorecard", and "Analytic Hierarchy Process" and generated a unified metric for supply chain performance analysis and sustainability. They also presented a real case study.

Hatefi and Jolai [11] considered uncertain parameters and facility disruptions. A robust model was proposed for an "integrated forward-reverse logistics network design". The model was formulated based on a "robust optimization 
approach" to protect the network against uncertainty. Furthermore, a mixed integer linear programming model with augmented p-robust constraints was proposed to control the reliability of the network among disruption scenarios. The objective function of the proposed model was minimizing the nominal cost, while reducing disruption risk using the p-robustness criterion

Azad et al. [12] studied the design problem of a" reliable stochastic supply chain network with random disruptions in the location of distribution centres and the transportation modes". The disruption could fail the whole of the capacity, or a fraction of it. The rest of demand can be served by other distribution centres. They solved the problem at two phases; the first is an exact solution method by reformulating the problem as a "second-order cone programming model", and the second is a hybrid algorithm combining "Tabu search" and "simulated annealing algorithms".

Marley et al. [13] adapted an "interactive complexity/tight coupling framework" to show how to mitigate disruptions with the use process simplification and the use of buffer inventories. The results of the analysis showed that "interactive complexity plays an important role in predicting the likelihood of supply chain disruptions". It was also found that "in more complex processes, increased buffers lead to an increased likelihood of supply chain disruptions occurring at downstream customers' facilities". The results suggested that "simplifying processes may mitigate normal supply chain disruptions". The empirical results were presented in the context of limitations from the archival data source. The data used for analysis were collected from one steel processing plant, which limited the generalizability of the results.

Taha et al. [14] proposed a genetic algorithm to design a reliable supply chain network under disruption with the objective of minimizing the design cost and regret cost. They combined three mitigation strategies: over-capacity production, inventory, outsourcing. They found that the regret and recovery costs represented a significant percentage of the total cost. The regret cost was even more significant for higher probabilities of disruptions. They proposed a facility fortification mitigation plan that showed high performance regarding demand satisfaction.

Sawik [15] considered the supply chain under disruption for single and multiple outsourcing mitigation strategies. The supplier selection as well as customer order scheduling were studied. The problem was formulated using mixed integer programming adding a risk measure. The objective was either to minimize the expected worst-case cost or to maximize the expected worst-case customer service level.

$\mathrm{Xu}$ et al. [16] used AnyLogic software. They modelled the supply chain as an agent system to study the supplier disruption and the recovery policies of the supply chain service level.

Ivanov et al. [17] presented a hybrid control-theoretic approach on the basis of optimal and feedback control to cope with the ripple effect in the disruption management of the supply chain.

Ivanov and Sokolov [18] proposed a model based on a combination of linear programming and optimal control to design a multi-period supply chain under disruption. Their mitigation plan included transportation reconfiguration.

$\mathrm{Hu}$ et al. [19] assumed supply disruption that was dichotomous. They assumed the supplier to have sufficient capacity to meet the order in case of no disruption. In case of disruption, the supplier would lose all capacity. They considered Restoration Enhancement strategy for supplier. The firm should use an incentive to motivate the supplier to invest in capacity restoration. Also, they studied the supplier diversification strategy, where the firm depends on reliable and unreliable suppliers. The results showed that restoration enhancement was preferred than supplier diversification strategy in case that the unreliable supplier restoration outcome was more predictable or when it is more likely to have a high restoration outcome.

Review articles that studied supply chains under disruption made a great contribution in the development of the research. Here are some recent review articles. $\mathrm{Xu}$ et all [20] presented a comprehensive bibliometric overview and visualization of the field of supply chain disruptions based on 1,310 publications. They found out that the number of publications in the domain of supply chain disruptions slightly increased during the years 1999 to 2012, but it increased sharply from 2012 to 2019. The paper pointed out the research gaps as well as the potential future research opportunities based on bibliometric analysis. The authors suggested considering transportation disruptions. They also suggested combining different methodologies to "mutually justify the correctness of the proposed managerial insights". They suggested combining quantitative modelling, simulations, and empirical studies. Hosseini et al [21] introduced a structured analysis and recommendations for which quantitative methods to be used at different levels of capacity resilience. They recommended developing a multi-objective two-stage stochastic model to build resilience capacity. Ivanov et al [22] classified the research streams and application areas for quantitative methods subject to different disruption risks and recovery measures. They highlighted the gaps in the research. They suggested for future work integrating operability objectives e.g., resilience, stability, and robustness, as new key performance indicators into supply chain disruptions decisions. They also suggested considering the temporary absence of some supply chain elements, as the previous research always considered complete absence of the elements. In this case, the research should consider the duration of disruptions with the recovery capacity and the recovery costs.

Govindan et al [23] presented a comprehensive review for supply chain network under disruption. Their review was divided into two parts. One for discussing the aspects related to supply chain management. The other for the reviewing the optimization techniques for dealing with uncertainty e.g., risk-averse stochastic programming, recourse-based stochastic programming, robust optimization, and fuzzy mathematical programming. One of their suggestions for future work was to study inventory and design decisions simultaneously for supply chains with highly perishable products, e.g., blood, under uncertainty. Snyder et al. [4] reviewed the literature on supply chain disruptions to provide an overview of the research questions that have been addressed. First, disruptions in the 
context of other forms of supply uncertainty were illustrated and the common modelling approaches were discussed. Then, a discussion on a nearly 150 scholarly works on the topic was presented, organized into six categories: evaluating supply disruptions; strategic decisions; sourcing decisions; contracts and incentives; inventory; and facility location. Heckmann et al. [24] reviewed the approaches for quantitative supply chain risk management by setting the focus on the definition of supply chain risk and related concepts.

The previous review can be summed up in the following points:

- There are several sources of disruptions: production capacity disruptions, supply disruption, demand uncertainty, transportation disruptions, and many others. Most of the research studied one type of disruption as in the work of Giri and B. R. Sarker [6], Sawik [15], Taha et al. [14], Taha et al. [8], Marley et al. [13], Xu et al. [16], Ivanov and Sokolov [18], Hasani and Khosrojerdi [7], and $\mathrm{Hu}$ et al. [19]. Only limited work considered two types of disruption at the same time, as in the work of Chen and Xiao [9], Hatefi and Jolai [11], and Azad et al. [12]

- Heuristic and conventional optimization techniques (e.g., linear and nonlinear programming) can be reliable in reaching an optimum solution. This was used by Sawik [15], Hasani and Khosrojerdi [7], Taha et al. [8], Hatefi and Jolai [11], and Azad et al. [12]. However, such techniques suffer from unsatisfactory performance for large-sized problems, when many assumptions need to be considered simultaneously. On the other hand, meta-heuristics (e.g., genetic algorithms) can obtain satisfying results for large-sized problems within acceptable computational time. That was used by Taha et al. [14], and Azad et al. [12]. Combining two solving techniques help find a better solution in relatively short computational time. That was applied in the work of Ivanov and Sokolov [18]. Simulation is even more capable of considering more assumptions and variables that help modelling a more realistic supply chain. That was used by [9], Xu et al. [16], and Ivanov [5].

- Adopting a mitigation strategy is one of the ways to decrease the negative impacts of supply chain disruptions. Several mitigation strategies have been studied in the literature, and several others have been suggested. Some research applied a single mitigation strategy (Giri and B. R. Sarker [6], Felice et al. [10], Taha et al. [8], and Ivanov and Sokolov [18]). Each mitigation strategy has its cons and pros. A strategy may perform well under one type of disruption, and badly under others. This creates a need to compare among strategies under different disruption types to help corporations decide which strategy to apply. Some researchers compared between two mitigation strategies as in the work of $\mathrm{Hu}$ et al. [19], Chen and Xiao [9], Sawik [15], and Marley et al. [13]. Limited research compared multiple mitigation strategies as Hasani and Khosrojerdi [7], and Ivanov [5]. Combined strategies have proven to have an emphasized effect in overcoming the disruption impacts that was proposed in the work of Taha et al. [14].
From the previous review, the motivation of this research is to fill the gap between realistic supply chains under disruption, and the studied model. Hence, the the contribution of this research is to take one more step towards a more realistic model for a supply chain under disruption. The research considers a supply chain under more than one type of disruption. The model combines more than one solving technique, including simulation. It compares multiple mitigation strategies versus multiple performance measures. The strategies include combined strategies.

A more formal problem statement: modelling a multiperiod supply chain under capacity and demand disruptions using Monte Carlo simulations and using integer linear programming for the optimization of the network. Five mitigation strategies will be investigated: higher production capacity, building inventory of finished product at the plants, working overtime shifts, combined inventory and higher production capacity, and combined inventory and overtime shifts. Several performance measures will be evaluated for each strategy.

The rest of the paper is organized as follows: Section 2 states the problem definition and assumptions. Section 3 presents the proposed model. Section 4 shows the results and the discussion; finally, section 5 presents the conclusion and the future work of this research.

\section{PROBLEM DEFINITION AND MODEL ASSUMPTIONS}

Supply chain network design is the phase when the company decides how to structure the supply chain over the next several planning periods. Strategic decisions include the location and capacities of production and warehousing facilities, the products to be manufactured or stored at various locations, the modes of transportation, etc. The supply chain configuration must support the strategic objectives of the company and increase the supply chain profit during this phase. When the supply chain is under disruption, the problem becomes even harder. Mitigation plans help overcome the negative influences of the disruption, although they add extra cost when disruptions do not occur. In this work, we study a multi-period supply chain that consists of two echelons: the plants, and the customers. It goes under operational disruptions which are capacity and demand disruptions. The capacity of the plants is subject to variability due to failure, availability, etc. This causes the capacity disruptions of the plants. Capacity disruption is

represented by a reduction in the capacity of plants; in terms of number of units produced. Such disruptions might be low, moderate, or high. They occur at a variable failure rate $(f r)$. Customer demand is subject to variability due to several reasons. This causes demand disruptions. This is represented by a demand variation percentage $(\delta)$ which may increase or decrease the average demand value $( \pm \delta)$. Its value is variable. For such supply chain five mitigation strategies are considered during the design phase of the supply chain. Integer linear programming is used to determine the links and the quantities flowing in the 
network. The mitigation strategies are evaluated using Monte Carlo simulation and compared to one another.

The proposed model has the following assumptions:

1. All potential plants have predetermined, deterministic capacities during regular operation.

2. The supplier capacity is indefinitely large.

3. All the links between the different echelons are available.

4. Customers' average demands are deterministic.

5. The failure probability of the plant capacities varies.

6. Demand variation percentage varies.

\subsection{Research methodology}

The research methodology for this work is summarized in the following steps:

\section{Step1: Select a mitigation plan}

Step2: Generate all the possible network designs of the supply chain. This is achieved by listing the possible combinations of potential plants being open or closed. By eliminating the combinations of having all plants closed, the number of possible network designs $(N)$ is calculated using Eq. (1).

$$
N=\left(2^{P}-1\right)
$$

Step3: Generate disruption scenarios over the planning periods by simulation. Each scenario (denoted by s) has its probability of occurrence $\left(P_{s}\right)$ according to the parameters set in the simulation.

Step4: Select a network design (n).

Step5: Run a disruption scenario over the planning periods using Monte Carlo simulation.

Step6: Use integer linear programming to find the optimum links and quantities of products flowing through the network design (n) under the selected disruption scenario (s) with the objective of minimizing the cost as will be given later in Eq. (4).

Step7: The cost resulting from the optimization of the integer linear programming model in step 6 is weighted by the probability of its scenario as in Eq. (2)

$$
\text { Cost }_{s}=\text { Cost }_{\text {optimum }} \times P_{S}
$$

Step8: Repeat steps 5 to 7 for other disruption scenarios, until all the scenarios are solved.

Step9: The overall cost of the network (n) selected in step 4 is the summation of the costs obtained in step 7 for all the scenarios as given in Eq. (3)

$$
\operatorname{Cost}_{n}=\sum_{s=1}^{S} \operatorname{Cost}_{s}
$$

Step10: Repeat steps 4 to 9 for another network (n), until all the networks generated in Step2 are solved.

Step11: Compare the overall cost Cost $_{n}$ calculated in step 9) of all networks. The network that provides the minimum cost is the optimum network for the mitigation strategy selected in Step1.

Step12: Repeat steps 1 to 11 for another mitigation strategy until all strategies are studied.

\section{Step13: END}

\section{PROPOSED MODEL}

The Supply Chain Network Design (SCND) is a critical stage in implementing an efficient and effective supply chain. Many models were proposed in literature for optimal SCND. However, most of the studies assumed that facilities are always reliable and available, and the working environment is stable. Such models fail to consider disruptions in the design phase and therefore lack countermeasures when disruptions do strike. The aim of this model is to consider mitigation strategies during the design phase of a multi-period supply chain network under operational disruptions. Then, the different mitigation strategies are evaluated and compared. Operational disruptions are capacity and demand disruptions that are studied independently and simultaneously. A Monte Carlo simulation is applied using Microsoft Excel to evaluate mitigation strategies regarding the cost, profit, percentage in full, and fill rate.

An Integer Linear Programming (ILP) is used to find the optimum links and quantities of products flowing through a certain design with the objective of minimizing the cost. Each mitigation strategy has specific constraints. However, some constraints are common. The main outline of the integer linear programming model used is given below.

\subsection{The integer linear programming model}

As mentioned in Step6 in Section 2, the integer linear programming model is used to find the optimum links and quantities of products flowing through the network design (n) under the selected disruption scenario (s).

Objective function. The objective function of the integer linear programming model is to minimize the total cost. The total cost includes several cost elements. Not all cost elements exist in all mitigation strategies. According to Eq. (4), the total cost consists of the fixed costs of operating plants $\left(F C_{p}\right)$, the transportation and production cost for quantities produced at regular shifts $\left(T C_{p} \cdot \operatorname{Qprod}_{p t}\right)$, transportation and overtime production cost for quantities produced during overtime shifts $\left(\operatorname{TC}_{p}^{\prime} \cdot\right.$ Qprod $\left._{p t}^{\prime}\right)$, the holding cost at inventories $\left(h \cdot Q i n v_{p t}\right)$, the unutilized capacity cost $\left(U\left(\operatorname{Cap}_{p}-\operatorname{Qprod}_{p t}\right)\right)$, and the losses due to shortage in satisfying the demand $\left(S C\left(Q d e l_{t}-\right.\right.$ Dem $\left.\left._{t}\right)\right)$.

Objective function: Minimize:

$$
\begin{aligned}
\operatorname{Cost}=\sum_{p=1}^{P}\left(F C_{p}+\sum_{t=1}^{T}\right. & \left(T C_{p} \cdot \operatorname{Qprod}_{p t}+T C_{p}^{\prime} \cdot \text { Qprod }_{p t}^{\prime}+h \cdot \operatorname{Qinv}_{p t}\right. \\
& \left.\left.+U\left(\operatorname{Cap}_{p}-\text { Qprod }_{p t}\right)+S C\left(\text { Qdel }_{t}-\text { Dem }_{t}\right)\right)\right)
\end{aligned}
$$


The previous cost elements may not be included all at the same time. It is according to the mitigation strategy that each cost element may or may not be considered. Likewise, constraints differ according to the mitigation strategy.

Plant capacity constraints: The quantity planned for production $\left(Q\right.$ plan $\left._{p t}\right)$ at plant $(p)$ during period $(t)$ should be less than the capacity of the plant as in Eq. (5). However, the actual quantity produced $\left(\operatorname{Qprod}_{p t}\right)$ is even lower because of the quantities reduced due to disruption as shown in Eq. (6).

$$
\begin{array}{cc}
\operatorname{Qplan}_{p t} \leq \operatorname{Cap}_{p} & \forall p, t \\
\operatorname{Qprod}_{p t}=Q \operatorname{plan}_{p t}-R_{p} & \forall p, t
\end{array}
$$

Integer constraints and non-negativity constraints for all the quantities are also imposed.

\subsection{Operational disruptions}

Since simulation allows considering different cases at the same time, the proposed simulation will study two types of disruptions simultaneously: capacity and demand disruptions. Capacity disruptions are represented as a reduction in the capacities of plants by value $\left(R_{p}\right)$. The level of disruption of each plant is low, moderate, or high. For simplicity, the probability of occurrence of the disruption is assumed to be the same for the three levels. This is called failure probability $(f r)$. The demand disruption is represented by fluctuation within a percentage $(\delta)$ of its average value as in Eq. (7).

$$
\begin{aligned}
(1-\delta) \cdot \operatorname{AvgDem}_{t} & \leq \operatorname{Dem}_{t} \\
& \leq(1+\delta) \cdot \text { AvgDem }_{t}
\end{aligned}
$$

\subsection{Mitigation strategies}

Five mitigation strategies are investigated and compared to the basic case of applying no mitigation strategy. These strategies are:

- Using higher production capacity machines

- Working overtime shifts

- Building inventory of finished products

- Combined inventory and working overtime shifts.

- Combined inventory and higher production capacity

The special constraints for the basic case and each of the

five mitigation strategies are given in the following subsections.

\subsubsection{Basic case: No mitigation strategy}

This case will be denoted as "regular production design" when comparing strategies in section 4 .

Plant capacity constraints: the following constraints are additionally considered. The surplus capacity of plant $(p)$ during period $(t)$ is the difference between the regular capacity and the quantity planned for production as shown in Eq. (8). Quantity produced from the surplus capacity of plant $(p)$ during period $(t)$ must be less than the surplus capacity of the plant as given in Eq. (9). It should be equal to the difference between demand and quantity produced as in Eq. (10).

$$
\begin{array}{ll}
\text { Capsur }_{p t}=\text { Cap }_{p}-\text { Qplan }_{p t} & \forall p, t \\
Q^{\prime} \text { sur }_{p t} \leq \text { Capsur }_{p t} & \forall p, t \\
Q^{\prime} \text { sur }_{p t}=\text { Dem }_{t}-\text { Qprod }_{p t} & \forall p, t
\end{array}
$$

Demand constraints: The sum of the quantity produced, and quantity used from surplus capacities of all the plants during period $(t)$ must be less than the demand of that period as formulated in Eq. (11).

$$
\sum_{p=1}^{p} \operatorname{Qprod}_{p t}+Q^{\prime} \text { sur }_{p t} \leq \operatorname{Dem}_{t} \quad \forall t
$$

\subsubsection{Using higher production capacity machines}

This mitigation strategy considers higher production capacities at the plants. In this case, the same constraints as the basic case are considered, except that the plant capacities are higher than those of the basic ones.

\subsubsection{Building inventory of finished products}

This mitigation strategy allows for inventory at the plants. The proposed model assumes that the inventory capacity is indefinitely large. It also assumes that the plant operates using full capacity. Units that are not delivered to the customers are held in the inventory.

Plant capacity constraints: The plant is planned to operate under full capacity whatever the demand was. This is formulated in Eq. (12). The actual quantity produced is as in Eq. (6) and Eq. (12).

$$
\operatorname{Qplan}_{p t}=\operatorname{Cap}_{p} \quad \forall p, t
$$

Inventory balance constraints: The entering quantities, as given in Eq. (13), are any extra quantities $\left(Q e x t_{p t}\right)$ that were produced in plant $(p)$ in excess of the demand of the period $(t)$, if they exist. The quantity remaining in the inventory of plant $(p)$ by the end of period $(t)$ is represented in Eq. (14). This is the sum of the quantities that were remaining by the end of the previous period $(t-1)$, and the difference between the entering and the used quantities $\left(Q^{\prime} i n v_{p t}\right)$ during period $(t)$.

$$
\begin{gathered}
=\left\{\begin{array}{l}
\left(\operatorname{Qprod}_{p t}-\operatorname{Dem}_{t}\right) \\
0 \quad \operatorname{Qprod}_{p t} \geq \operatorname{Dem}_{p t} \\
\operatorname{Qprod}_{p t}<\operatorname{Dem}_{i}
\end{array}\right) \\
\operatorname{Qinv}_{p t}=\operatorname{Qinv}_{p t-1}+\text { Qext }_{p t} \\
-Q i n v_{p t}^{\prime}
\end{gathered}
$$

Demand constraints: The quantity delivered to the customer from all plants during period $(t)$ should not exceed the demand during this period. The quantity 
delivered is represented by the sum of the quantity produced, and the quantity used from the inventory of all plants during the period. This is shown in Eq. (15)

$$
\sum_{p=1}^{p}\left(\operatorname{Qprod}_{p t}+\operatorname{Qinv}_{p t}^{\prime}\right) \leq \operatorname{Dem}_{t} \forall p, t
$$

\subsubsection{Working Overtime shifts}

Plant capacity constraints: The surplus capacity of plant $(p)$ during period $(t)$, as shown in Eq. (16), is the difference between the regular capacity and the quantity planned for production. Units produced from the surplus capacity of plant $(p)$ during period $(t)$ must be less than the surplus capacity of the plant as given in Eq. (17).

Units produced from surplus capacity of plant $(p)$ during period $(t)$ equals the difference between demand and quantity produced as in Eq. (18).

Quantity produced using the overtime of plant $(p)$ during period $(t)$ must not exceed overtime capacity of the plant. This is formulated in Eq. (19).

$$
\begin{array}{cc}
\operatorname{Capsur}_{p t}=\text { Cap }_{p}-\text { Qplan }_{p t} & \forall p, t \\
Q^{\prime} \text { sur }_{p t} \leq \text { Capsur }_{p t} & \forall p, t \\
Q^{\prime} \text { sur }_{p t}=\text { Dem }_{t}-\text { Qprod }_{p t} & \forall p, t \\
\operatorname{Qprod}_{p t}^{\prime} \leq \text { Cap }_{p}^{\prime} & \forall t
\end{array}
$$

Demand constraints: During period $(t)$, the quantity delivered to the customer from all plants should not exceed the demand. The quantity delivered to the customer is the sum of the quantities regularly produced at the plants, the quantities produced using the surplus capacity, and the quantities produced using the overtime capacity of the plants. This is formulated in Eq. (20).

$$
\begin{aligned}
& \sum_{p=1}^{p}\left(\operatorname{Qprod}_{p t}+\right.\left.Q^{\prime} \text { sur }_{p t}+\operatorname{Qprod}_{p t}^{\prime}\right) \\
& \leq \operatorname{Dem}_{t} \forall t
\end{aligned}
$$

\subsubsection{Combined mitigation strategies}

Constraints of two combined mitigation strategies is a combination of the constraints of both strategies.

\subsection{Performance measures}

Different performance measures can be used to evaluate the results of a certain mitigation strategy. Monte Carlo simulation is used for this evaluation over many time periods under many disruption scenarios. The selected performance measures are:

\subsubsection{Total cost of the supply chain}

This includes both the fixed cost, and the variable cost for operating the plants as in Eq. (4).

\subsubsection{Profit of the supply chain}

The profit of the supply chain, as in Eq. (21), is the difference between the revenue and the total cost. The revenue is the product of the selling price and the quantities delivered to the customer. The total cost is as given in Eq. (4).

$$
\text { Profit }=S P \cdot\left(\sum_{t=1}^{T} Q \operatorname{del}_{t}\right)-T C
$$

\subsubsection{Supply chain robustness}

The indicator of the supply chain robustness is the shortage cost, for simplicity. Minimizing the shortage cost of the disruption scenario corresponds to maximizing the supply chain robustness. This is calculated as in Eq. (22).

$$
\begin{aligned}
& \text { Shortage cost of scenario }(s) \\
& =\sum_{s=1}^{S} P_{s} \times S C \times Q_{d i s}
\end{aligned}
$$

\subsubsection{Percentage in full}

The percentage in full represents the percentage of the number of time intervals $\left(n^{\prime}\right)$ when the customer received exactly its demand, with respect to the total time intervals (T). The percentage in full is formulated in Eq. (23).

$$
\text { Percentage in full }=\frac{n^{\prime}}{T} \%
$$

\subsubsection{Average fill rate}

The average fill rate is the average value of the fill rate among all periods $(T)$. The fill rate of one period is the ratio between the delivered quantities to the customer and his demand. This is given in Eq. (24).

$$
\text { Average fill rate }=\frac{\sum_{t=1}^{T}\left(\frac{\text { del }_{t}}{\text { Dem }_{t}}\right)}{T}
$$

\section{COMPUTATIONAL RESULTS AND DISCUSSION}

The Monte Carlo simulation model was applied using Microsoft Excel as a tool to evaluate the five performance measures for the five mitigation strategies. The parameters used for the integer linear programming, and the simulation are shown in Table 1. The values for mitigation strategies are given in Table 2 . 
Table 1. Parameters for Linear Programming and Monte Carlo Simulation

\begin{tabular}{|c|c|}
\hline Parameter & Value \\
\hline Production cost per unit & $\mathrm{PC}=10$-unit cost \\
\hline Selling price per unit & $\mathrm{SP}=5 \times \mathrm{PC}$ \\
\hline $\begin{array}{l}\text { Transportation and production } \\
\text { cost between echelons per unit }\end{array}$ & $\mathrm{TP}=1.1 \times \mathrm{PC}$ \\
\hline Unutilized capacity unit cost & $\mathrm{U}=0.5 \times \mathrm{PC}$ \\
\hline Shortage unit cost & $\mathrm{SC}=3 \times \mathrm{PC}$ \\
\hline $\begin{array}{l}\text { Overtime transportation and } \\
\text { production unit cost }\end{array}$ & $T C^{\prime}{ }_{p}=2.5 \times \mathrm{PC}$ \\
\hline Plant fixed cost & $\begin{array}{l}F C_{p}=\text { Max. plant } \\
\text { capacity } \times \text { PC }\end{array}$ \\
\hline Regular plant capacity & $\begin{array}{l}\operatorname{Cap}_{p}=500 \\
\text { units/plant }\end{array}$ \\
\hline $\begin{array}{l}\text { Capacity disruption at each } \\
\text { plant (Low level) }\end{array}$ & $R_{p}=-1$, and -5 units \\
\hline Parameter & Value \\
\hline $\begin{array}{l}\text { Capacity disruption at each } \\
\text { plant (Moderate level) }\end{array}$ & $\begin{array}{l}R_{p}=-4, \text { and }-20 \\
\text { units }\end{array}$ \\
\hline $\begin{array}{l}\text { Capacity disruption at each } \\
\text { plant (High level) }\end{array}$ & $\begin{array}{l}R_{p}=-20, \text { and }-100 \\
\text { units }\end{array}$ \\
\hline Failure probability & $\begin{array}{l}\text { fr }=0 \%, 5 \% \text {, and } \\
10 \%\end{array}$ \\
\hline Average Demand & $\begin{array}{l}\text { AvgDem } \\
\text { units }\end{array}$ \\
\hline Demand variation & $\begin{array}{l}\delta=0 \%, 5 \%, 10 \%, \\
15 \%, 20 \%, 25 \%\end{array}$ \\
\hline
\end{tabular}

In order to compare the performance of all mitigation strategies, results are divided into groups according to the performance measure under study. For each performance measure, the results of all the strategies are compared in two sets of experiments. The two sets represent two operational disruptions schemes. In the first set of experiments, only demand disruptions occur, without capacity disruption. In the second set of experiments, both demand and capacity disruptions occur.

\section{Table 2. Values for mitigation strategy}

\begin{tabular}{|l|l|}
\hline $\begin{array}{l}\text { Mitigation strategy / } \\
\text { Parameter }\end{array}$ & Range \\
\hline High production capacity \\
\hline Increased capacity & $\begin{array}{l}1.1 \times \text { Max. plant } \\
\text { capacity }\end{array}$ \\
\hline Inventory & Unlimited \\
\hline Inventory capacity in units & $0.1 \times$ PC \\
\hline Holding unit cost per unit & \\
\hline Overtime
\end{tabular}

\begin{tabular}{|l|l|}
\hline Overtime capacity in units & $\begin{array}{l}0.1 \times \text { Max. plant } \\
\text { capacity }\end{array}$ \\
\hline Overtime unit cost per unit & $2 \times \mathrm{PC}$ \\
\hline
\end{tabular}

\subsection{Supply chain cost}

To study the behaviour of different mitigation plans regarding the total cost, five cost elements are individually quantified in the results to better understand the performance of the strategy. The cost elements are the total production cost, the penalty cost, the unutilized capacity cost, the overtime cost, and the holding cost. The results of the first set of experiments; with demand disruption only, are shown in Fig. 1 to Fig. 6.

As expected, the total cost is directly proportional to the demand variation percentage. Comparing Fig. 1 to Fig. 4, the value of the total cost is comparable in the four cases of regular design, higher capacity strategy, overtime strategy, and inventory strategy. However, the cost elements of the four cases are not the same. In the regular production design (Fig. 1), the shortage cost is the highest of all strategies and increases as the demand variation increases. This can be interpreted as the demand variation increases, the regular production cannot satisfy the increased demand, and shortage cost is added. In the higher capacity strategy in Fig. 2, the production cost represents the main component of the total cost. The overtime strategy (Fig. 3) behaves the same as the higher capacity strategy because both strategies lead to increased production quantities. In both strategies the shortage cost and the unutilized cost slightly exist at higher demand variations. This can be interpreted as the higher variation the demand is highly increased or decreased leading to added shortage cost and added unutilized capacity cost. The cost elements of the inventory strategy in Fig. 4 are also comparable to the previous mitigation strategies; production cost is the main cost element, but the shortage cost is very low, with relatively high holding cost. This means that the inventory capacity was higher than the increase in demand in the high demand variations. Fig. 5, and Fig. 6 show the combined mitigation strategies. Their total costs are remarkably higher than the previous ones. Their main cost element is the holding cost. It is more than the sum of all other costs. This indicates that the demand was much lower than the available quantities produced and kept in inventory. A remarkable difference exists between both strategies in Fig. 5 and Fig. 6. The inventory and overtime strategy (Fig. 5) have a low total cost for low demand variations. As the demand variation increases, the total cost increases. The increase is mainly due to the increase in holding cost. However, total cost in the inventory and higher capacity strategy (Fig. 6) is high for all values of demand variation. The holding cost is the main component. 


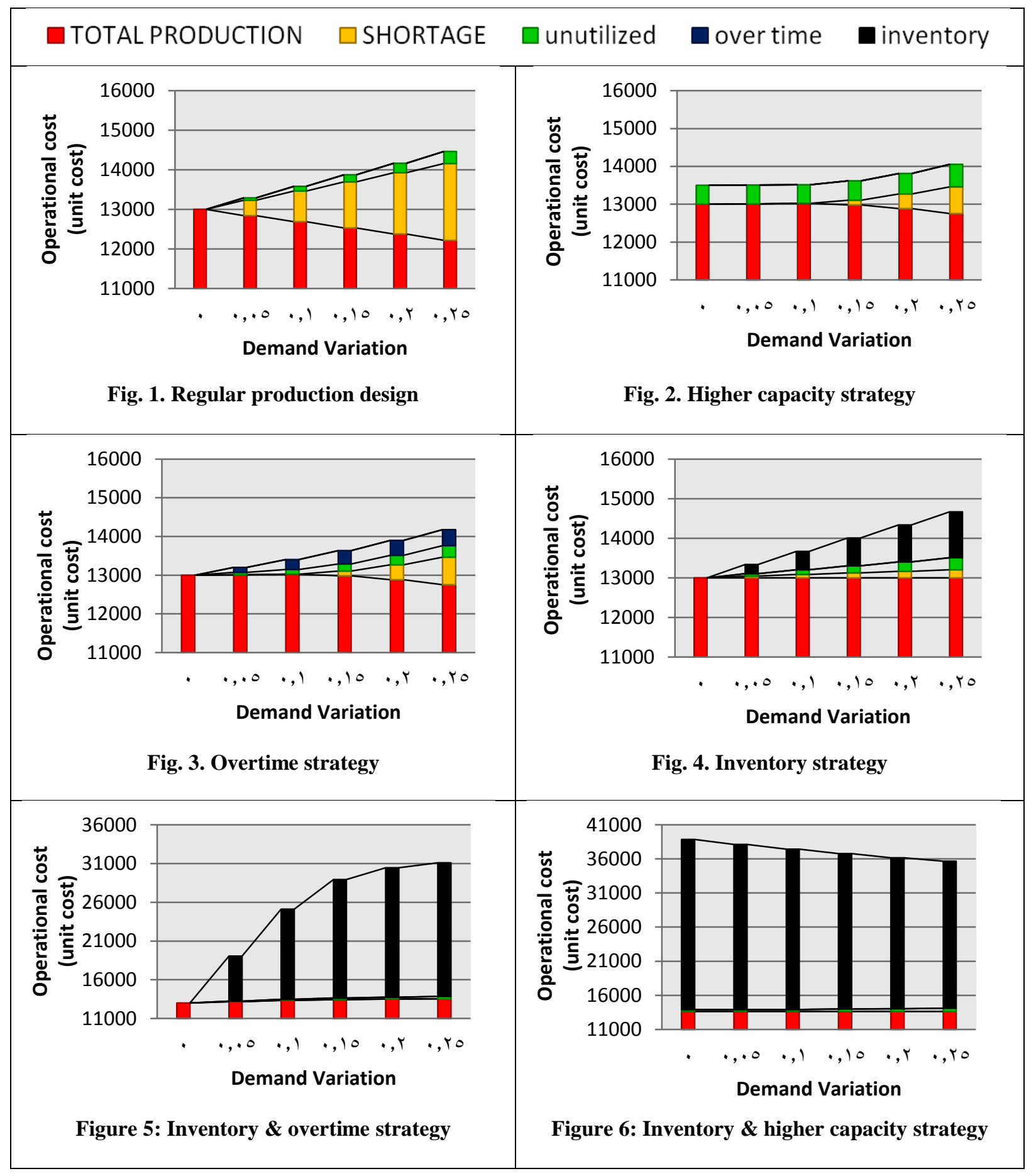

The main difference between both is that the higher capacity strategy produces increased amounts in all intervals as there is inventory capacity to keep the for later demand. However, in case of overtime, the produced quantities are limited, especially for low demand variation.

For the second set of experiments, both demand and capacity disruptions occur. The failure probability for capacity disruption is $(f r=0.1)$. Results of total cost for different strategies are given in Fig. 7 to Fig. 12.

The behaviour of the regular production design, and the three single mitigation strategies (Fig. 7 to Fig. 10) are very close to their complements in Fig. 1 to Fig. 4 respectively in the first set of experiments when no capacity disruptions occurred. The increased shortage cost is the main difference between both sets as the capacity disruptions lead to decreased production. This consequently leads to an increase in the shortage cost, and hence in the total cost.

Remarkable differences show in the combined mitigation strategies. For the inventory and overtime strategy (Fig. 11) the production cost is higher than before in Fig. 5. However, the total cost is much lower as the inventory cost decreased than before. For the inventory and higher capacity strategy in Fig. 12, the production cost increases, and the holding cost decreases compared to Fig. 6 such that the total cost highly decreases. The reason for this change is attributed to decreased production resulting from the 
capacity disruption. This means less quantities are produced, less quantities are held in the inventory, less holding cost, and less total cost.

\subsection{Supply chain profit}

Here we compare between different mitigation strategies from the profit point of view. The results of the first set of experiments; with demand disruptions only, are illustrated in Fig. 13.

From Fig. 13, it is found that in case of zero demand variation, the profit of all strategies (except the two strategies with higher initial capacity) is the same and equal to the maximum value. For the higher capacity strategy, the profit decrease by the amount of fixed cost related to the higher capacity instalment. For the combined strategy of higher capacity with inventory consideration the profit decrease by both the fixed cost and the holding cost of the inventory built during the periods and not utilized. In case of higher demand variation $5 \%$ to $20 \%$, the overtime strategy has the highest profit. However, the difference between the overtime strategy and the inventory strategy is relatively small compared to the difference with the other strategies. In case of high variation in demand more than $20 \%$, the inventory strategy only has the highest profit.

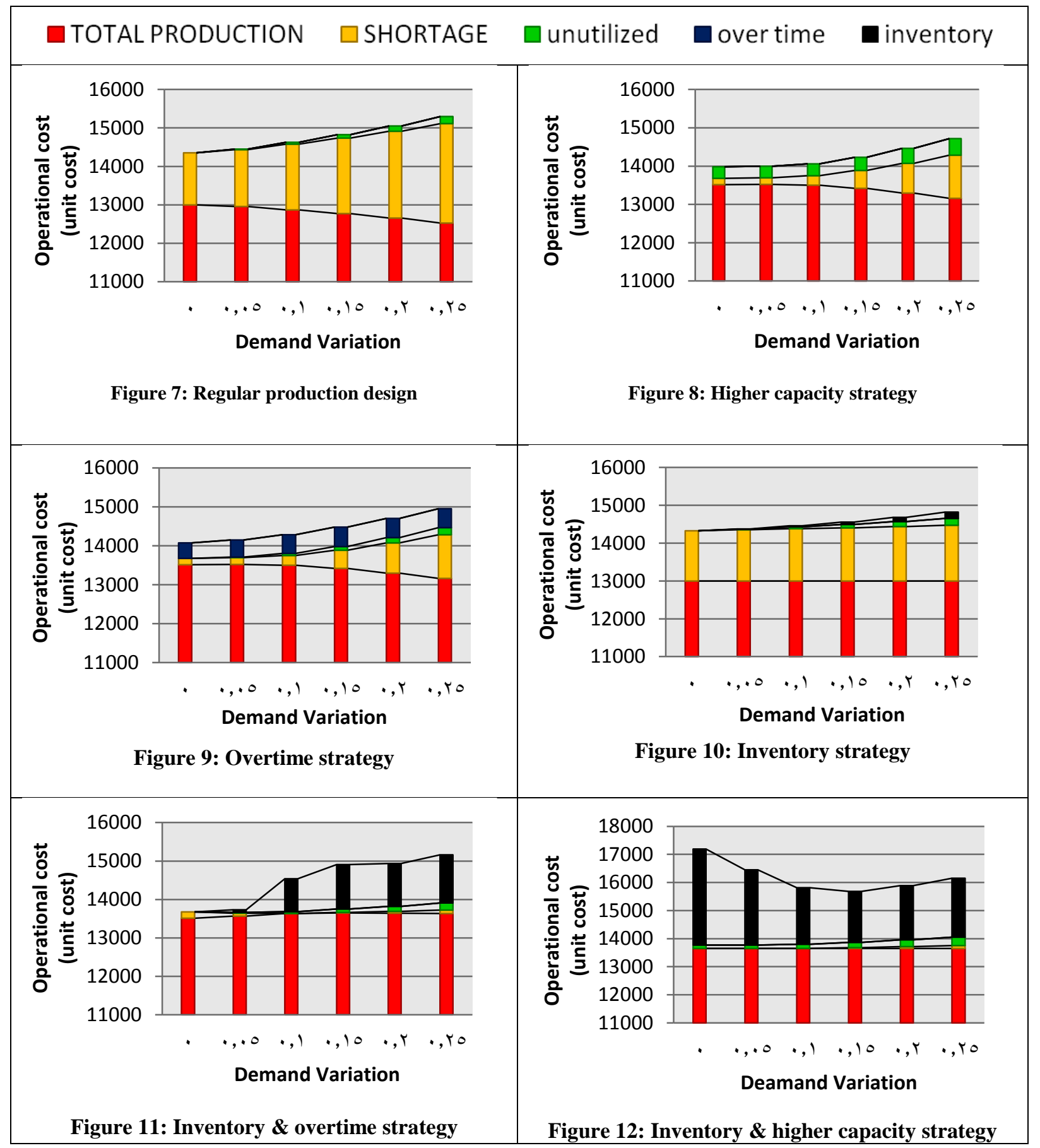


The results of the second set of experiments; in which both demand and capacity disruptions occur, are shown in Fig. 14. The inventory and overtime strategy yields the highest profit. This is because this strategy allows the use of built-up inventory from the periods of low demand and the use of overtime in case the amount in the inventory is insufficient. At very high demand variation (25\%) and capacity disruptions, this strategy has significantly higher profit than the other strategies.

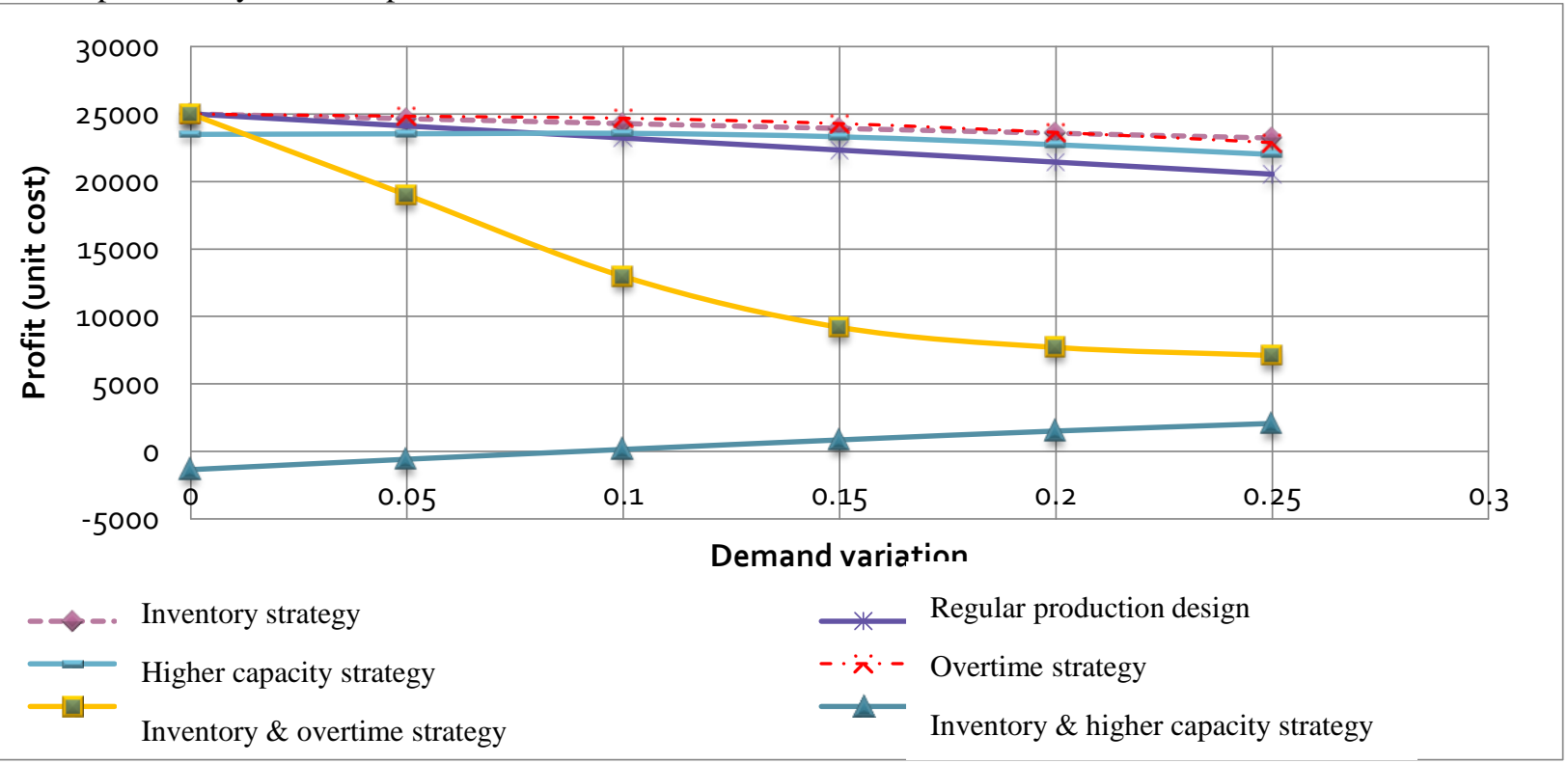

Figure 13: The profit under demand disruption only

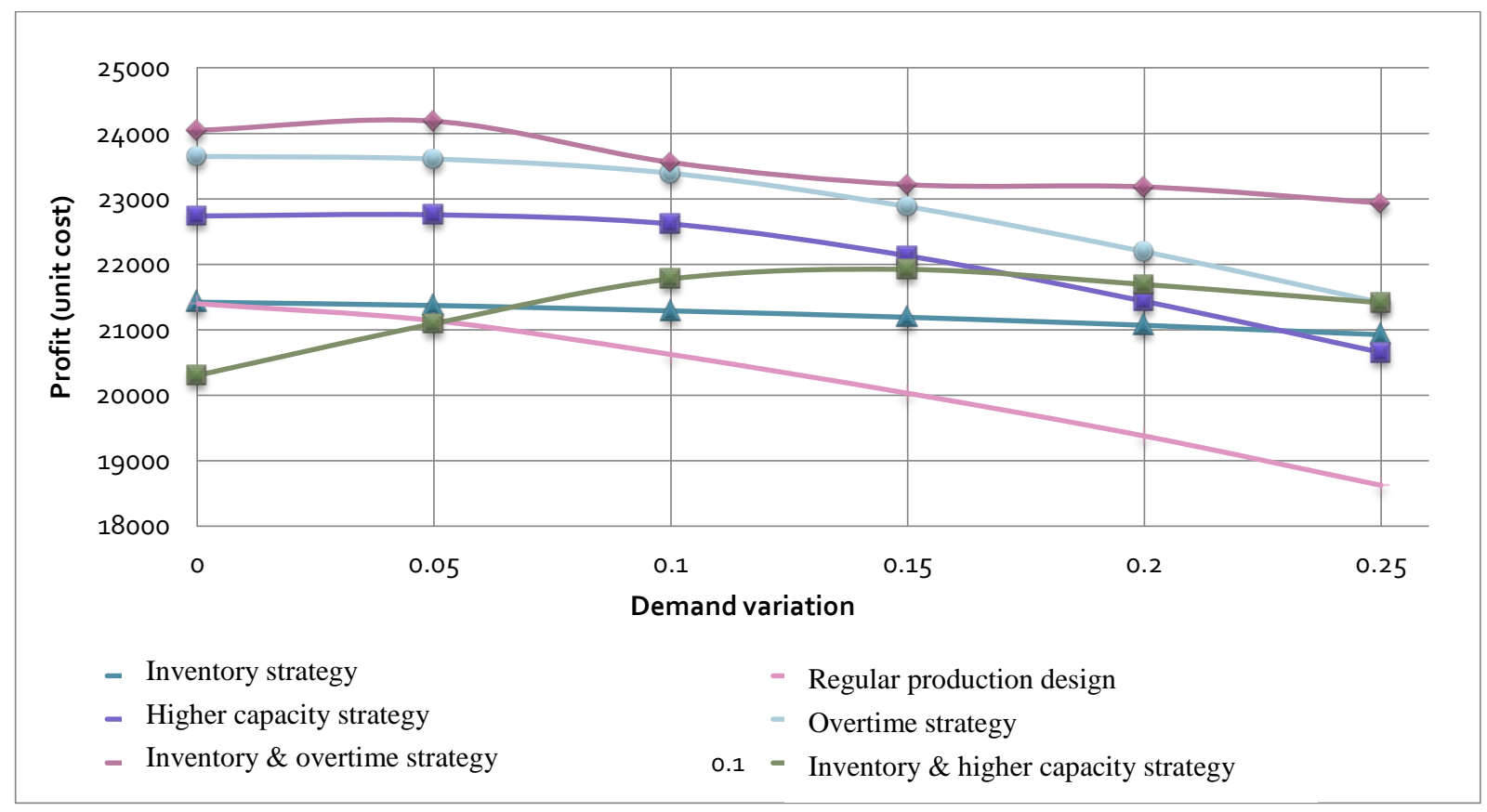

Figure 14: The profit under demand and capacity disruptions

\subsection{Supply chain robustness}

The robustness is measured in terms of disruption cost, represented by the shortage cost. In the first set of experiments, with demand disruption only, two strategies have the highest robustness. This is shown in Fig. 15. The most robust strategy is the one with the lowest shortage cost. This is the case for the combined inventory and overtime strategy. The strategy of combined inventory and higher capacity comes second, while the inventory strategy is the third. It is clear that building inventory has a significant effect on the shortage cost. This is because using the inventory will allow the network to recover from the disruptions easily. This is even emphasized in combined strategies where extra capacity is allowed. Fig. 16 illustrates the second set of experiments of demand and capacity disruptions. The inventory and higher capacity strategy is the most robust at lower demand 
variations. However, as the demand variation increases the robustness of the strategy applying both inventory and overtime is more competitive.

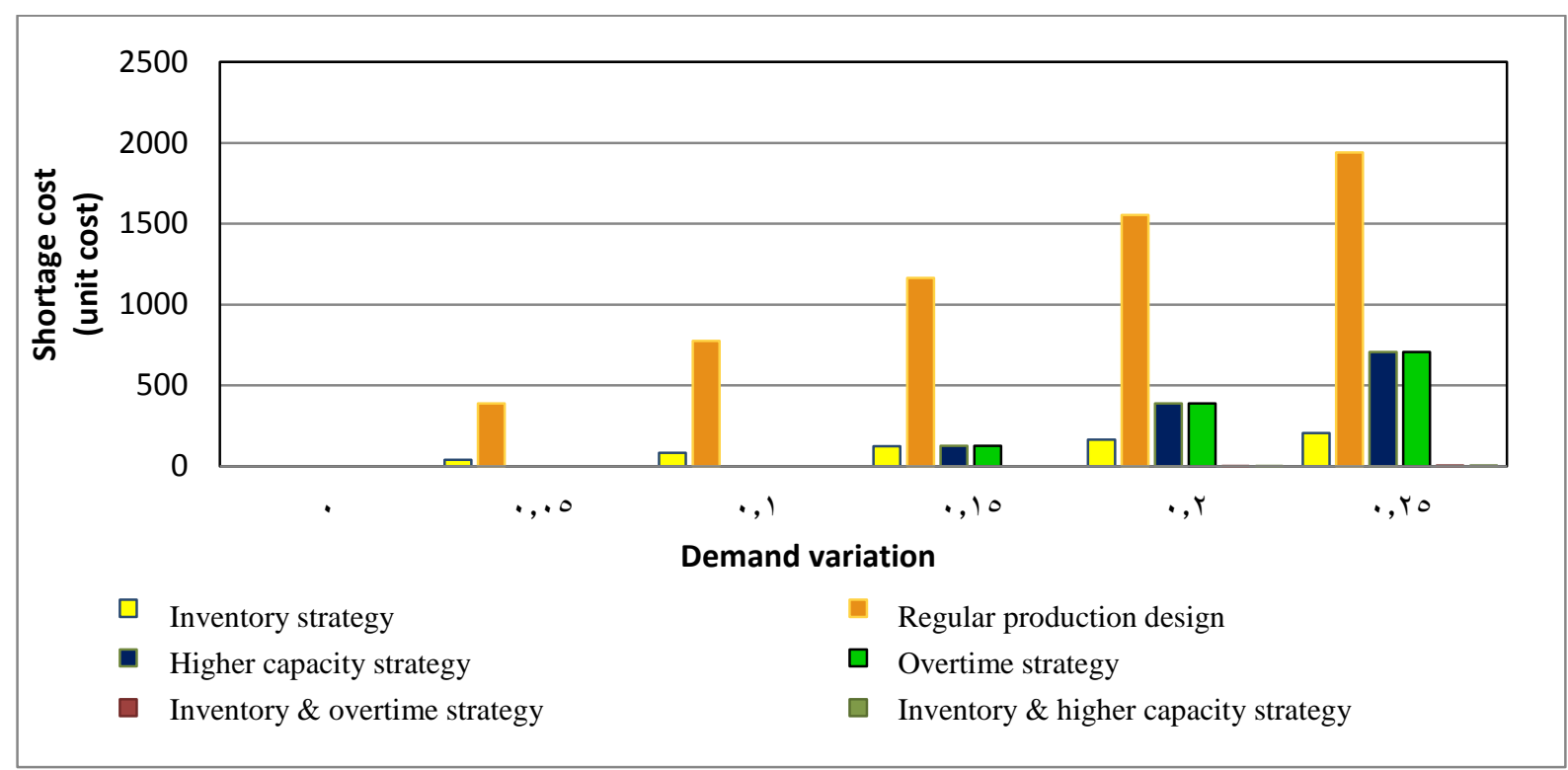

Figure 15: Shortage Cost under demand disruption only

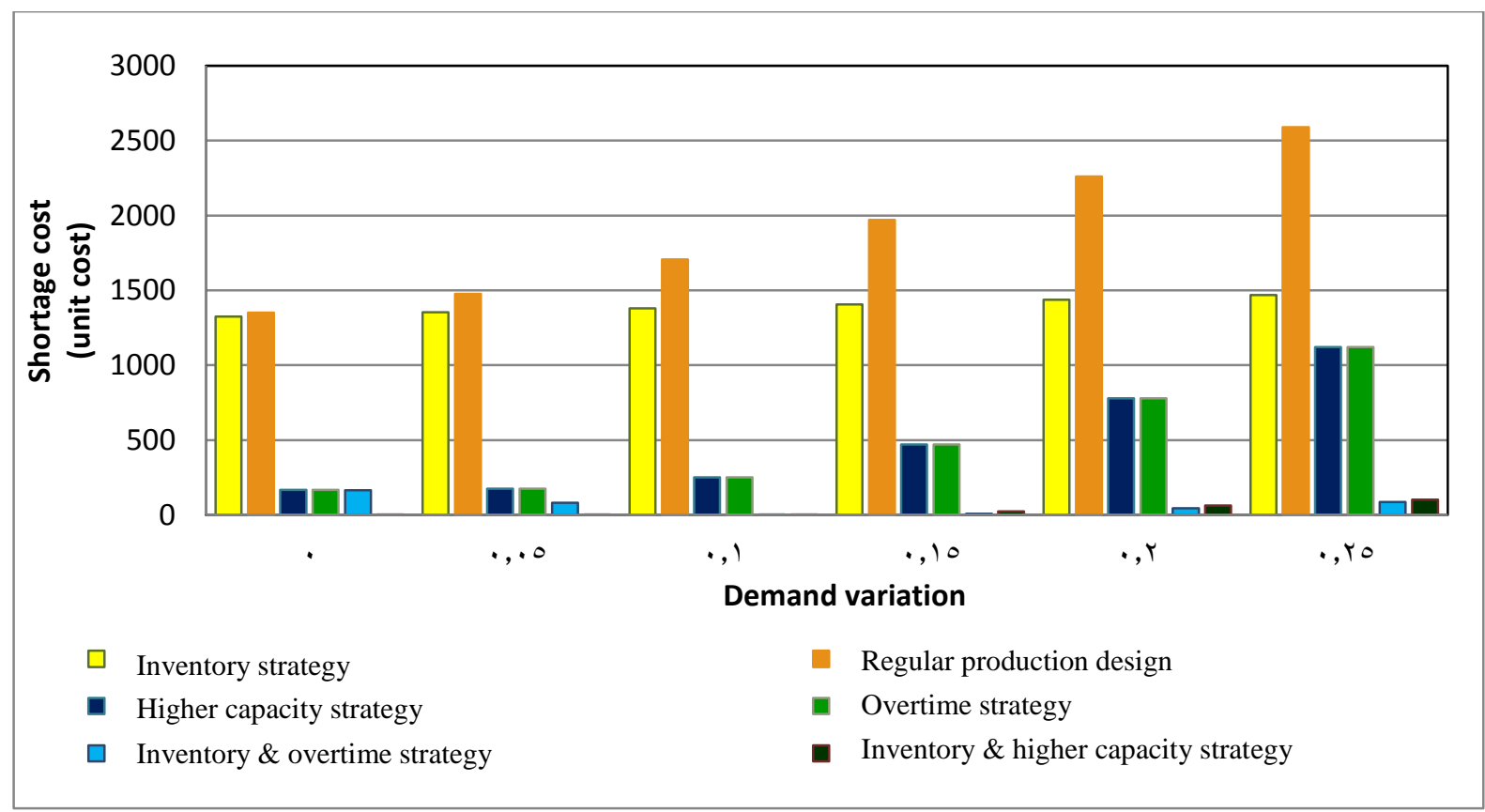

Figure 16: Shortage cost under demand and capacity disruptions

\subsection{Percentage in full}

The effect of the different strategies on the percentage in full is shown in Fig. 17 and Fig. 18. For the first set of experiments with demand disruption only, the percentage of orders delivered in full fall to $50 \%$ for the regular production design. However, the combined inventory and overtime strategy, and the combined inventory and higher capacity strategy are not affected by the demand disruption. All of these statements can be observed from Fig. 17. The second set of experiments is under demand and capacity disruption. At the zero-demand variation, the best strategy regarding the percentage in full is the combined inventory and higher capacity strategy as shown in Fig. 18. However, for higher demand variation, the combined inventory and overtime strategy becomes 
competitive. The regular production design has the worst behaviour regarding the percentage in full for all demand variations.

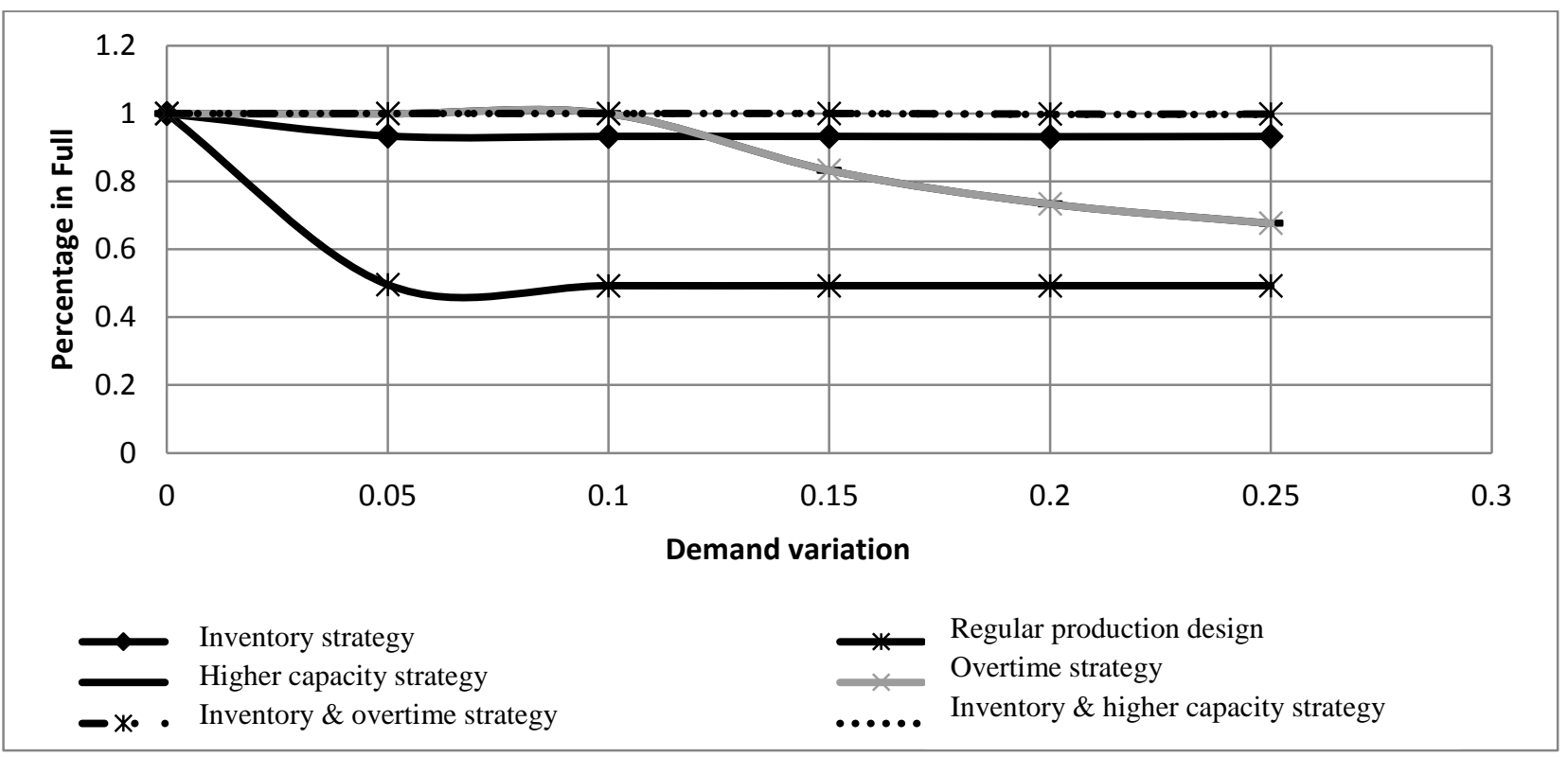

Figure 17: Percentage in full under demand disruption only

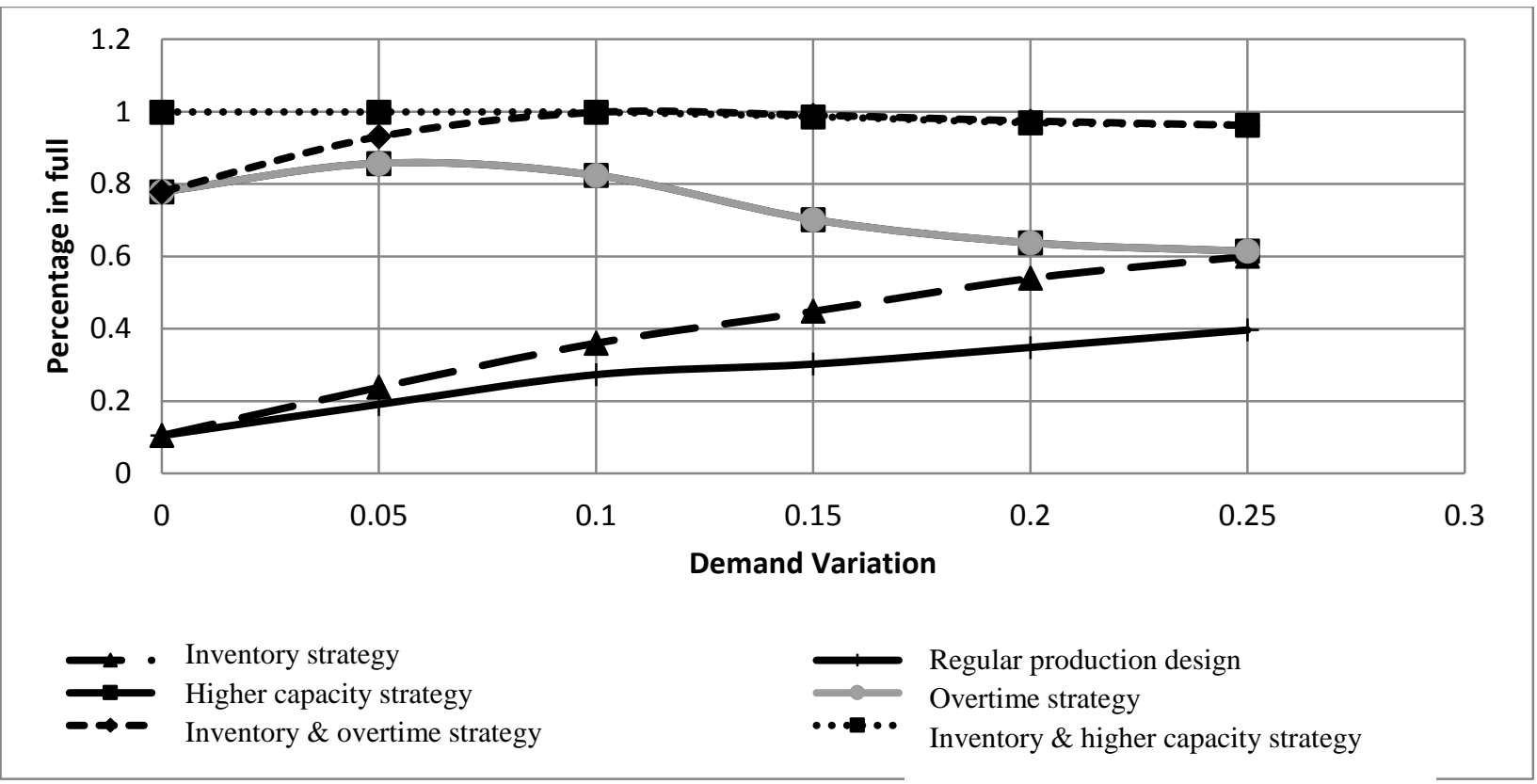

Figure 18: Percentage in full under demand and capacity disruptions

\subsection{Average fill rate}

The last performance measure is the average fill rate. Results of this measure are illustrated in Fig. 19 and Fig. 20. For the first set of experiments with demand disruption only, all plans have $100 \%$ fill rate at zero demand variation (Fig. 19). However, as demand variation increases the average fill rate for different strategies behave differently. Regular production design decreases significantly till it reaches $94.5 \%$ fill rate. The higher capacity strategy, and the overtime strategy almost coincide, and decrease to
98\%. All the strategies that include inventory have the highest fill rate. The inventory strategy decreases slightly to $99.5 \%$. The combined strategies almost coincide at the $100 \%$ fill rate at all demand variations.

For the second set of experiments under demand and capacity disruptions, again, the combined strategies almost coincide for the best fill rate at all demand variations. The higher capacity strategy and the overtime strategy almost coincide and have the second-best performance. The inventory strategy is not affected by the demand variation. 
The regular production design gives the worst fill rate for all demand variation percentages.

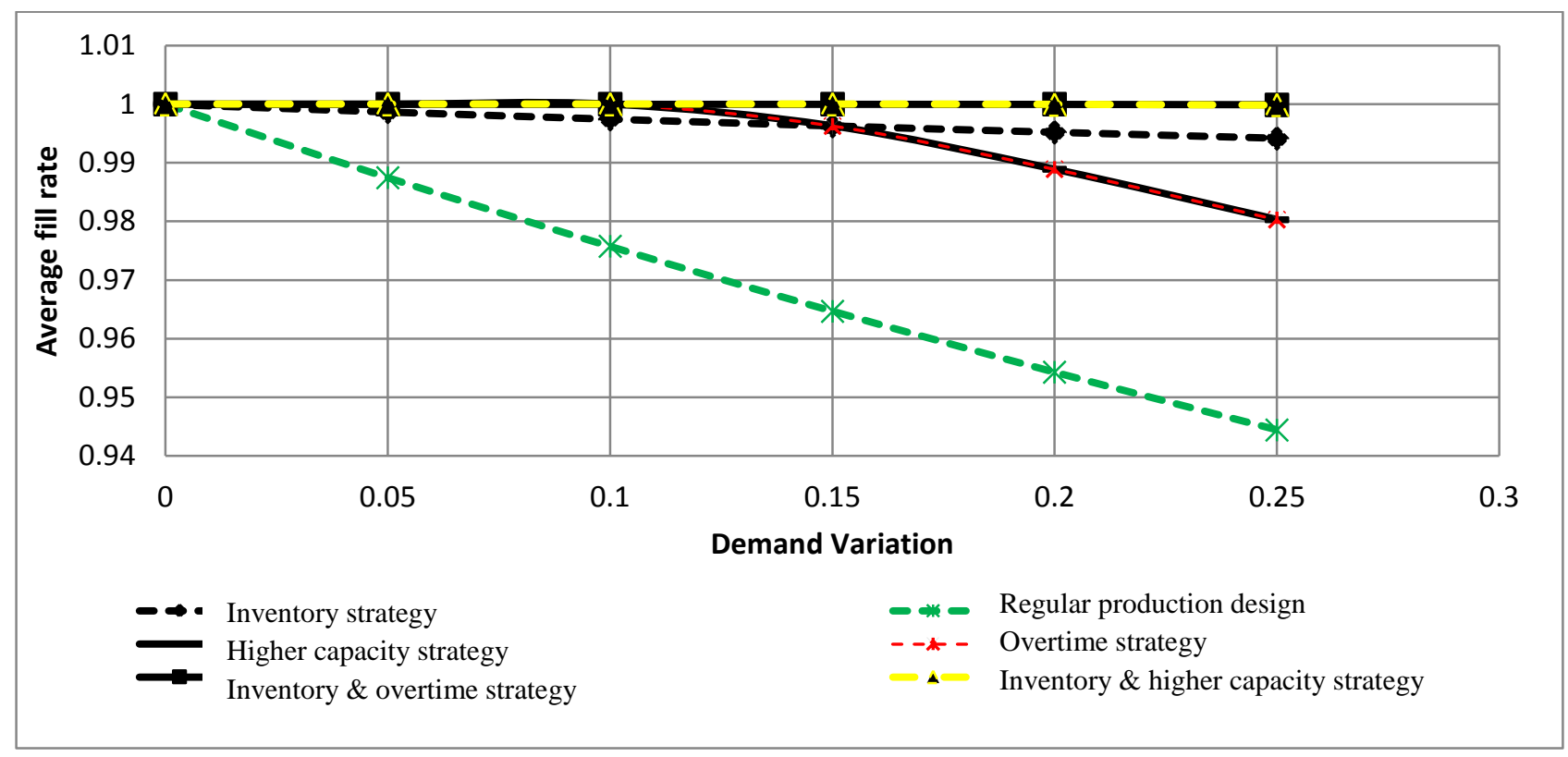

Figure 19: Average fill under demand disruptions only

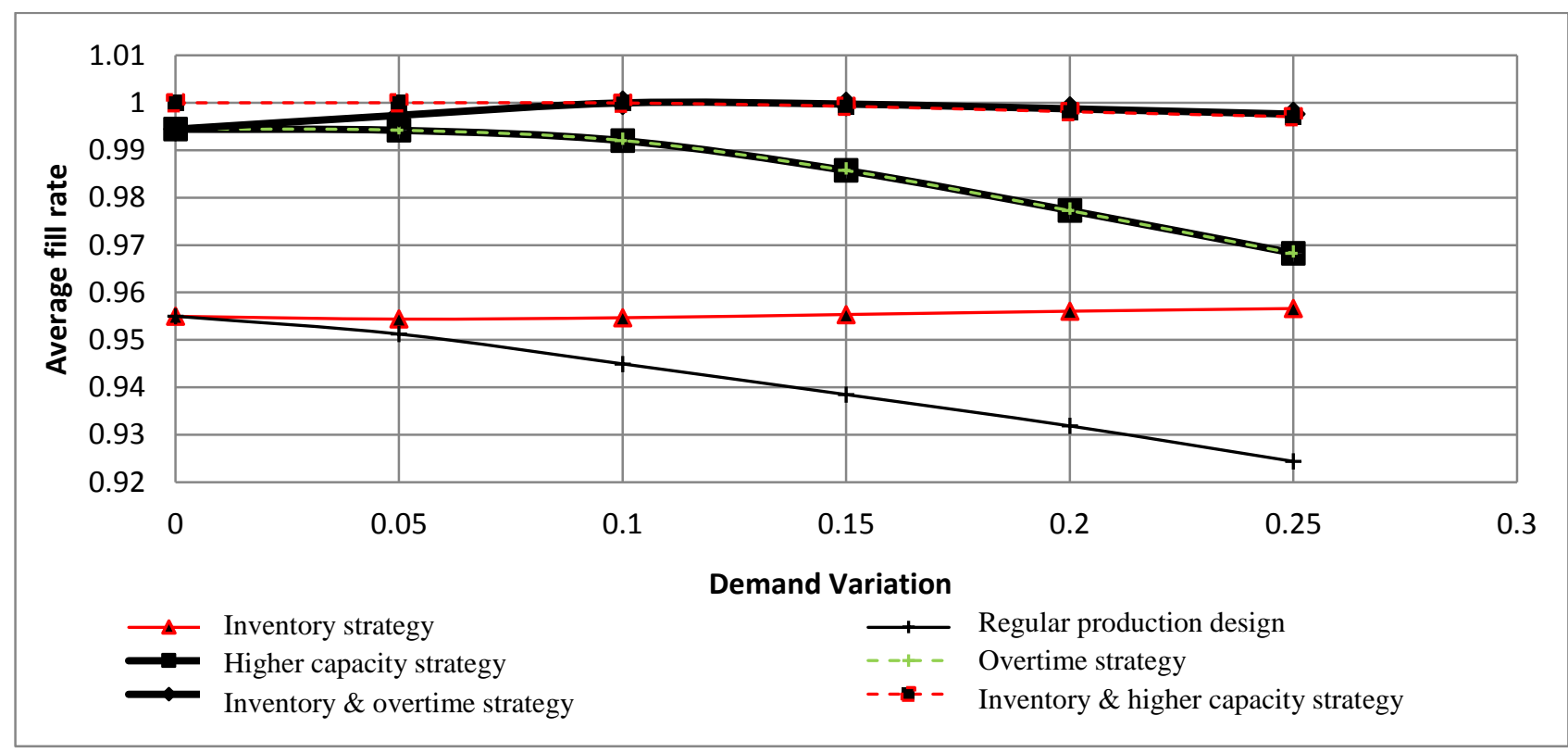

Fig. 20. Average fill rate under demand and capacity disruptions

\subsection{Comparison of Mitigation strategies for Different Performance measures under study}

To better evaluate and compare mitigation strategies, all strategies are compared with regards to the five performance measures. Extra results were added considering capacity disruption only. In Table 3 , six columns represent the regular case, and the five mitigation strategies, while the rows represent the five performance measures: with three disruption cases for each measure. The three cases are: "C" for capacity disruption only, "D" for demand disruption only, and " $\mathrm{C}+\mathrm{D}$ " for capacity and demand disruptions simultaneously. Extra rows were added for the average of some performance measures, and for the sum, and the average of all measures.

For each performance measure, the six cases are ranked according to their performance. The strategy of the worst performance is ranked " 0 ". The strategy of the best performance is ranked " 5 ". The strategies in-between are ranked each according to its order. Strategies of the same performance are ranked equally. Shading colours are used on the table to indicate good and bad performance.

For the cost and profit performance measures, the averages of these two measures are compared. The 
overtime strategy is the best. Its score is either " 5 " or " 4 " for all cases, and it scored " 5 " for the average. However, the combined inventory and higher capacity strategy is the worst. Its score is " 0 " for all cases and scored " 0 " for the average. For the robustness, percentage in full, and fill rate performance measures, the averages of these three measures are compared. The combined inventory and higher capacity strategy is the best. Its score is " 5 " for all cases, and it scored " 5 " for the average. However, the regular production design is the worst. Its score is " 0 " for all cases and scored " 0 " for the average. For the overall performance in all performance measures, the averages of all measures are compared. This is the same rank of the strategies according to the sum. The combined inventory and overtime strategy is the best. Its average scored " 5 ". The regular production design is the worst. Its average scored " 0 ". Other findings from Table 3 , it is noticed that for all strategies (except the combined strategy of inventory and higher capacity) their performance in case of capacity disruption only differs from that in case of demand disruption only. It is also noticed that the combined strategy of inventory and higher capacity is either the best or the worst for different performance measures. It never ranked in-between.

Table 3. Comparison performance measures for mitigation strategies.

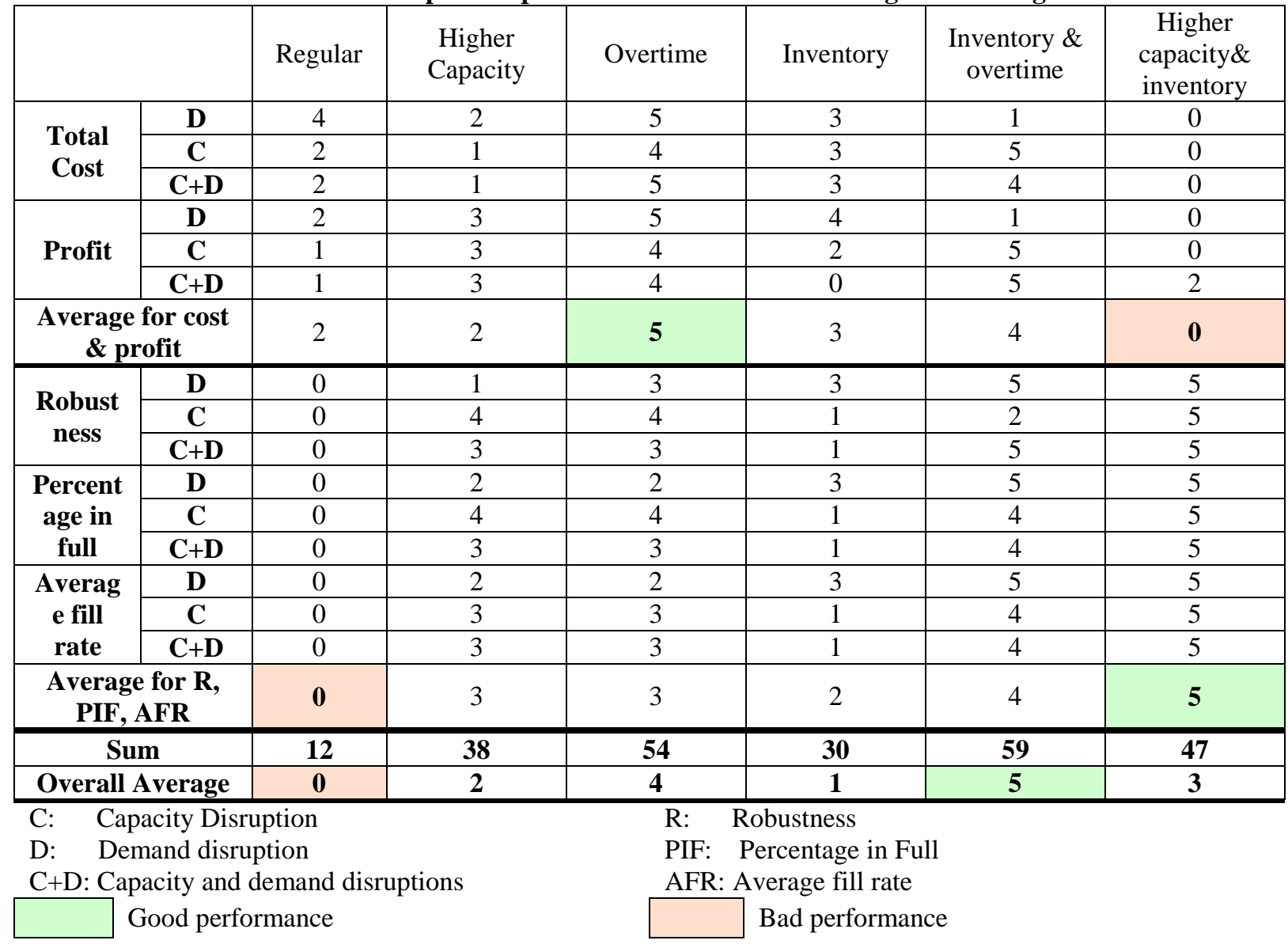

\subsection{Managerial implications}

This research provides some useful insights for decision makers in case of supply chain disruptions to choose among the mitigation strategies according to their priorities. From the collective results of Table 3, and the discussion of the previous section, the following are the recommendations to the decision makers.

For "money" priorities, the overtime strategy is the best. For the network robustness and customer satisfaction priorities, the combined inventory and higher capacity strategy is the best. For the overall performance priority (both money and robustness priorities), the best strategy is the combined inventory and overtime strategy.

\section{CONCLUSIONS}

A multi-period supply chain under capacity and demand disruptions was modelled using Monte Carlo simulations and using integer linear programming with the objective of minimizing the total cost. Five mitigation strategies were investigated: higher production capacity, building inventory of finished product at the plants, working overtime shifts, combined inventory and higher production capacity, and combined inventory and overtime shifts. Five performance measures were used to evaluate each strategy. The results emphasized the fact that every mitigation strategy has its cons and pros. The performance of any 
mitigation strategy highly depends on the type of disruption, and on the performance measure examined.

High performance resulted from the following cases: The strategy of building inventory performs the best for the performance measures related to the cost and profit. The combined inventory and higher capacity strategy is the best for the performance measures related to the network robustness and customer satisfaction.

Unsatisfactory performance resulted from the following cases: The combined inventory and higher capacity strategy is the worst regarding the cost and profit. The regular production design is the worst regarding the cost and the profit.

When evaluating the overall performance, the best strategy is the combined inventory and overtime strategy, while the worst is the regular production design.

Future work can include further investigation of other types of disruptions such as disruptions in transportation as well as studying the nature of capacity disruptions and demand disruptions. More analysis for the operational performance of the supply chain for different design structures and different types of products can be conducted. Moreover, considering stochastic cost parameters can be applied to better describe the problem.

\section{Credit Authorship Contribution Statement:}

Raghda Taha: conceptualization, formal analysis, investigation, resources, original draft.

Amin El-Kharbotly: methodology, validation, supervision, formal analysis, review

Yomna Sadek: validation, supervision, formal analysis, writing, review and editing.

\section{Declaration of Competing Interest}

The authors declare that they have no known competing financial interests or personal relationships that could have appeared to influence the work reported in this paper.

\section{References}

[1] R. K. Oliver, and M. D. Webber, "Supply-chain management: logistics catches up with strategy," Outlook, vol 5 (1), 1982, pp. 42-47.

[2] B. J. La Londe, "Supply Chain Management: Myth or Reality?" Supply Chain Management Review, vol 1 (1), 1997, pp. 6-7.

[3] A. Kumar, S. Luthra, S. Mangla, Y. Kazançoğlu, "COVID-19 impact on sustainable production and operations management," Sustainable Operations and Computers, vol (1), 2020, pp. 1-7.

[4] L. V. Snyder, Z. Atan, P. Peng, Y. Rong, A. J. Schmitt, B. Sinsoysal, "OR/MS Models for Supply Chain Disruptions: A review," IIE Transactions, vol 48 (2), 2016, pp. 89-109.

[5] D. Ivanov, "Revealing Interfaces of Supply Chain Resilience and Sustainability: A Simulation Study," Int. J. Prod. Res., vol 56 (10), 2018, pp.3507-3523.

[6] B. C. Giri, B. R. Sarker, "Improving performance by coordinating a supply chain with third party logistics outsourcing under production disruption," Comput. Ind. Eng., vol 103, 2017, pp. 168-177.
[7] A. Hasani and A. Khosrojerdi, "Robust global supply chain network design under disruption and uncertainty considering resilience strategies: a parallel memetic algorithm for a real-life case study," Transp. Res. Part E Logist. Transp. Rev., vol 87, 2016, pp. 20-52.

[8] R. Taha, Y. Sadek, A. El-Kharbotly, N. Afia, K. Abdallah, "Multi-Objective Supply Chain Network Design Under Demand Uncertainty Using Robust Goal Programming Approach," Proceedings of International Conference on Operations Excellence and Service Engineering, 2015, pp. 827-836.

[9] K. Chen, T. Xiao, "Outsourcing strategy and production disruption of supply chain with demand and capacity allocation uncertainties," Int. J. Prod. Econ., vol 170, 2015, pp. 243-257.

[10] F. De Felice, A. Petrillo, C. Autorino, "Development of a framework for sustainable outsourcing: Analytic balanced scorecard method (A-BSC)," Sustain., vol 7 (7), 2015, pp. 8399-8419.

[11]S. M. Hatefi and F. Jolai, "Robust and reliable forward-reverse logistics network design under demand uncertainty and facility disruptions," Appl. Math. Model., vol 38 (9-10), 2014, pp. 2630-2647.

[12]N. Azad, H. Davoudpour, G. Saharidis, M. Shiripour, "A new model to mitigating random disruption risks of facility and transportation in supply chain network design," Int. J. Adv. Manuf. Technol., vol 70 (9-12), 2014, pp. 1757-1774.

[13]K. Marley, P. Ward, J. Hill, "Mitigating supply chain disruptions - a normal accident perspective," Supply Chain Manag., vol 19 (2), 2014, pp.142-152.

[14] R. Taha, K. Abdallah, Y. Sadek, A. El-Kharbotly, N. Afia, "Design of Supply Chain Networks with Supply Disruptions using Genetic Algorithm," 25th annual POMS conference proceedings, Atlanta, USA, 2014.

[15] T. Sawik, "Computers \& Operations Research Optimization of cost and service level in the presence of supply chain disruption risks: Single vs. multiple sourcing," Comput. Oper. Res., vol 51, 2014, pp. 1120.

[16] M. Xu, X. Wang, L. Zhao, "Predicted supply chain resilience based on structural evolution against random supply disruptions," Int. J. Syst. Sci.: Oper. Logist., vol 1(2), 2014, pp. 105-117.

[17] D. Ivanov, B. Sokolov, A. Dolgui, "The ripple effect in supply chains: Trade-off 'efficiency-flexibilityresilience' -in disruption management," Int. J. Prod. Res., vol 52(7), 2014a, pp. 2154- 2172.

[18] D. Ivanov and B. Sokolov, "Control and systemtheoretic identification of the supply chain dynamics domain for planning, analysis, and adaptation of performance under uncertainty," Eur. J. Oper. Res., vol 224 (2), 2013, pp. 313-323.

[19] X. Hu, H. Gurnani, L. Wang, "Managing risk of supply disruptions: Incentives for capacity restoration," Prod. Oper. Manag., vol 22 (1), 2013, pp.137-150.

[20] S. Xu, X. Zhang, L. Feng, W. Yang, "Disruption risks in supply chain management: a literature review based 
on bibliometric analysis," Int. J. Prod. Res., vol 58 (11), 2020, pp. 3508-3526.

[21] S. Hosseini, D. Ivanov, A. Dolgui, "Review of quantitative methods for supply chain resilience analysis," Transp. Res. Part E Logist. Transp. Rev., vol 125, 2019, pp. 285-307.

[22] D. Ivanov, A. Dolgui, B. Sokolov, M. Ivanova, "Literature Review on Disruption Recovery in the Supply Chain,” Int. J. Prod. Res., 55 vol 20, 2017, pp. 6158-6174.

[23] K. Govindan, M. Fattahi, E. Keyvanshokooh, "Supply chain network design under uncertainty: A comprehensive review and future research directions," Eur. J. Oper. Res., vol 263, 2017, pp. 108-141.

[24]I. Heckmann, T. Comes, S. Nickel, "A critical review on supply chain risk - Definition, measure and modelling," Omega, vol 52, 2015, pp. 119-132. 